\title{
EFECTO DE LA TEMPERATURA Y SALINIDAD EN LA GERMINACIÓN Y CRECIMIENTO INICIAL DE UN MATERIAL NATURALIZADO DE Lotus tenuis WALDST. \& KIT
}

\author{
Marinoni, l. ${ }^{1} ;$ Zabala, J. M. ${ }^{2} ;$ Patiño, J. ${ }^{1}$ \& Pensiero, J. F. ${ }^{1,2}$
}

\begin{abstract}
RESUMEN
Lotus tenuis Waldst. \& Kit es una leguminosa perenne tolerante a la salinidad, con dificultades en su implantación en el centro-norte de Argentina debido al estrés térmico e hídrico sufrido durante el verano. En el presente estudio se evaluó el comportamiento germinativo y crecimiento inicial de una población naturalizada de L. tenuis del centro-norte de Santa Fe, comparado con el cultivar comercial Aguapé. Se analizaron diferentes temperaturas constantes y alternas de germinación y se evaluó el crecimiento inicial en condiciones controladas de luz y temperatura, en ausencia y presencia de estrés salino. Altas temperaturas afectaron negativamente la germinación en ambos materiales, en ausencia y presencia de salinidad, hallándose la mayor tolerancia a salinidad a la temperatura constante más baja y alterna. La presencia de sales afectó la producción de biomasa en crecimiento inicial, aunque la partición no se vio afectada. El cv. comercial Aguapé, presentó mayor producción de biomasa que el material naturalizado.
\end{abstract}

Palabras clave: pastizales, estrés térmico, estrés salino, Lotus tenuis.

\begin{abstract}
Effect of temperature and salinity in germination behaviour and initial growth in a naturalized material of Lotus tenuis Waldst. \& Kit.

Establishment of the perennial forage legume Lotus tenuis Waldst. \& Kit is difficult in central-north areas of Argentina because thermal and water stressful conditions during summer. In the present study, germination behavior and initial growth was evaluated for a naturalized population of $L$. tenuis from center-north of Santa Fe province and it was compared with the Aguapé commercial
\end{abstract}

1.- Programa de Documentación, Conservación y Valoración de la Flora Nativa. Facultad de Ciencias Agrarias (Universidad Nacional del Litoral). 86-Kreder 2805 (3080HOF) Esperanza, provincia de Santa Fe. Email: lmarinoni@fca.unl.edu.ar

2.- Consejo Nacional de Investigaciones Científicas y Técnicas (CONICET).

Manuscrito recibido el 14 de junio de 2017 y aceptado para su publicación el 2 de agosto de 2017. 


\section{Marinoni et al.}

cultivar. Constant and alternating germination temperatures and initial growth, under controlled conditions of light and temperature, were assessed under salinity stress. Higher temperatures negatively affect the germination of both materials, under stressful and non-stressful conditions. Salinity tolerance was higher at lower constant temperature and alternating. Salinity negatively affects biomass production in initial growth although biomass allocation was not affected. The cv. Aguapé showed a better behavior than naturalized material.

Key words: rangelands, thermal stress, salt stress, Lotus tenuis.

\section{INTRODUCCIÓN}

La producción ganadera extensiva del centro-norte de Argentina utiliza como fuente principal de forraje los pastizales naturales, con un escaso aporte de tecnología. Esto se ha acentuado ante el avance de la agricultura a áreas antes consideradas marginales, desplazando la ganadería a ambientes con múltiples limitantes (13; 42). El crecimiento y la productividad de las pasturas en estas zonas están limitados por ciclos alternados de excesos y déficits hídricos. Los suelos, en su mayoría son heterogéneos, pobremente drenados, con bajo contenido de nutrientes y altos contenidos de sales (27). Los cultivares de forrajeras adaptados a esta región son escasos, en particular los de leguminosas.

El uso de especies del género Lotus en pasturas se ha incrementado en el mundo debido a su plasticidad y productividad en un amplio rango de suelos (7). Lotus tenuis Waldst. \& Kit, conocido vulgarmente como "lotus", "trébol de pájaro" o "lotus de hoja angosta", es una leguminosa perenne originaria de Europa, introducida en nuestro país alrededor de 1930, difundiéndose en la región de la Pampa Deprimida (8), en suelos asociados a diferentes comunidades vegetales, donde el $\mathrm{pH}$ en superficie varía entre 6-9, con diferente contenido de sales y pobres en fósforo y nitrógeno $(24 ; 28 ; 32 ; 33 ; 34)$. Si bien es común hallarla en los bajos dulces (29), ensayos experimentales han demostrado tolerancia a condiciones de estrés por $\mathrm{NaCl}$ $(3 ; 5 ; 44)$, dado por la capacidad de excluir iones $\mathrm{Na}^{+}(18 ; 19 ; 20 ; 31 ; 41)$, al igual que otras leguminosas forrajeras $(43 ; 48 ; 54)$.

Lotus tenuis es considerada clave para el manejo de los sistemas ganaderos de la región de la Pampa Deprimida de la provincia de Buenos Aires debido a su capacidad para incorporar nitrógeno atmosférico al suelo, en simbiosis con bacterias fijadoras, interferir en el establecimiento de malezas o especies de pobre valor forrajero, mejorar la calidad y digestibilidad del forraje e incrementar la productividad primaria de los pastizales $(1 ; 9 ; 12 ; 16 ; 21$; 26). Los cambios en la calidad del forraje por la incorporación de esta especie se traducen en mayores ganancias de peso vivo de novillos y vaquillonas, respecto a otras leguminosas forrajeras $(4 ; 9 ; 10)$.

$\mathrm{Si}$ bien se han identificado variedades de $L$. tenuis menos sensible a altas temperaturas estivales, en comparación con otras leguminosas templadas como Lotus uliginosus, Trifolium fragiferum, $T$. hybridum, T. pratense y T. repens (3), y se han obtenido buenos resultados en la germinación de L. tenuis a $20-25{ }^{\circ} \mathrm{C}(17$; 